\title{
Correlation between psoriasis' severity and waist-to-height ratio*
}

\author{
Gleison Vieira Duarte
}

\author{
Larissa Porto da Silva ${ }^{2}$
}

\begin{abstract}
In the absence of ideal biomarkers, the research for clinical markers correlated to the severity of psoriasis and/or its comorbidities becomes crucial. Recently, studies have shown positive correlation between body mass index and prevalence and severity of psoriasis. Abdominal circumference showed stronger correlation with disease severity than body mass index. We evaluated the waist-to-height ratio in a sample of 297 adult patients with psoriasis and observed that it has a significant correlation with body mass index and PASI, and together with body mass index allows the identification of central obesity, reducing its subdiagnosis.
\end{abstract}

Keywords: Anthropometry; Comorbidity; Obesity; Psoriasis

We have previously demonstrated that the severity of psoriasis measured by PASI (Psoriasis Area Severity Index) in a Brazilian population presents a significant correlation with anthropometric measurements, such as Body Mass Index (BMI), Waist-to-Hip Ratio (WHR) and Waist Circumference (WC), especially the last two. ${ }^{1}$

Recent studies show that Waist-to-height Ratio (WhtR) has a stronger correlation with cardiovascular diseases than WC. ${ }^{2,3}$ Paller and cols. (2013) demonstrated that children with psoriasis have greater averages of WhtR than non-affected children. As it is not adequate for different ethnicities/ages, muscle mass levels, bone structure and not measuring central adiposity, BMI does not seem to be the best method for follow-up of patients with psoriasis even though it is still the most recommended by all guidelines. ${ }^{5,6,7} \mathrm{We}$ performed a cross-sectional study in which minimum sampling size (292) was calculated based on obesity prevalence in Bahia, around 5\%, according to data from IBGE 2002 - 2005 Pesquisa de Orçamentos Familiares (Family Budgets Survey). A prevalence variation of $5 \%$ was considered, and then the formula $\mathrm{N}=$ z.p.q/ $\mathrm{d}^{2}$ was used, where $\mathrm{Z}=1.96, \mathrm{P}=$ prevalence, $\mathrm{Q}=(1-\mathrm{P})$ and $\mathrm{d}=$ error margin $( \pm 2.5 \%)$. New and subse- quent patients were enrolled, totaling 296 patients in the period from October/2008 to August/2010. We evaluated WhtR in a sample of 297 adult patients with psoriasis, 289 of which had complete anthropometric measurements.

A structured questionnaire was used for data collection. The results of the obesity prevalence study were previously published ${ }^{1}$. Descriptive statistics were done with the help of SPSS version 20.0 for Windows, the continuous variables described through means ( \pm standard deviation) as well as medians and interquartiles, while categorical variables were described as proportions. The quantitative variables studied were submitted to the normality test of KolmogorovSmirnov. The significance level adopted was of 5\%.

The mean \pm standard deviation (SD) of PASI for the sample was of $8.1 \pm 7.8$ (median 5.3; p25=2.7 and $\mathrm{p} 75=10.9$ ). WhtR varied from $0.38-0.92$ with mean \pm SD of $0.57 \pm 0.08$ and median of 0.56 .

PASI for the 243 patients with WhtR $\geq 0.5$ had a median of 5.7, significantly greater than in the 48 patients with WhtR <0.5, 3.7 (Mann Whitney; $\mathrm{p}=0.03$ ). Correlation between WhtR and BMI was of 0.86 (Spearman, $\mathrm{p}<0.01)$. Correlation between $\mathrm{Wht} \mathrm{R}$ and PASI was of 0.14 (Spearman, $\mathrm{p}=0.01$ ).

\footnotetext{
Received on 09.06.2013.

Approved by the Advisory Board and accepted for publication on 09.09.2013.

* Work performed at Universidade Federal da Bahia (UFBA) - Salvador (BA), Brazil.

Conflict of interest: None

Financial funding: None

Universidade Federal da Bahia (UFBA) - Salvador (BA), Brazil.

Escola Bahiana de Medicina e Saúde Pública - Salvador (BA), Brazil.

(C)2014 by Anais Brasileiros de Dermatologia
} 
TABLE 1: Comparison of abnormal findings of WhtR and BMI based on cutoff points for obesity

\begin{tabular}{llll}
\hline Anthropometry & BMI $<\mathbf{3 0 k g} / \mathbf{m} 2$ & BMI $>\mathbf{3 0 k g} / \mathbf{m} 2$ & Total \\
WhtR $<0.5$ & 46 & 0 & 46 \\
WhtR $>0.5$ & 161 & 82 & 243 \\
Total & $\mathbf{2 0 7}$ & $\mathbf{8 2}$ & $\mathbf{2 8 9}$ \\
\hline
\end{tabular}

Table 2: Distribution of WhtR frequencies and description of subgroups as per BMI cutoff points ("normal", "overweight" and "obese"). BMI in $\mathrm{kg} / \mathrm{m}^{2}$

\begin{tabular}{lllll}
\hline WhtR frequencies & $\mathbf{N} ; \%$ & BMI $<25$ & BMI $>\mathbf{2 5 < 3 0}$ & BMI $>\mathbf{3 0 k g}$ \\
$0.38+0.44$ & $11 ; 3 \%$ & $11(100 \%)$ & 0 & 0 \\
$0.44+0.5$ & $35 ; 12 \%$ & $33(94 \%)$ & $02(6 \%)$ & 0 \\
$0.5 \mathrm{H} 0.92$ & $243 ; 84 \%$ & $51(21 \%)$ & $110(45 \%)$ & $82(33 \%)$ \\
\hline
\end{tabular}

Among 243 patients with alteration in anthropometric measure (BMI or WhtR), only $82(33 \%)$ were detected by BMI (Table 1). In table 2 we observed that 110 patients whose WhtR showed obesity were classified as "overweight" instead of "obese" by BMI. When WhtR was $<0.5$, no obese patient was found according to BMI.

The importance of a clinical marker correlated to the severity of psoriasis resides in the fact that we still do not have ideal biomarkers. ${ }^{8}$ WhtR is found to be an accessible method, with an equal cutoff point for both sexes, correlated to obesity, cardiovascular disease and diabetes mellitus., ${ }^{2,3}$ Considering that there is

\section{REFERENCES}

1. Duarte GV, Oliveira Mde F, Cardoso TM, Follador I, Silva TS, Cavalheiro CM, et al. Association between obesity measured by different parameters and severity of psoriasis. Int J Dermatol. 2013;52:177-81.

2. Wakabayashi I. Necessity of Both Waist Circumference and Waist-to Height Ratio for Better Evaluation of Central Obesity. Metab Syndr Relat Disord. 2013;11:189-94.

3. Xu Z, Qi X, Dahl AK, Xu W. Waist-to-height ratio is the best indicator for undiagnosed Type 2 diabetes. Diabet Med. 2013;30:e201-7.

4. Paller AS, Mercy K, Kwasny MJ, Choon SE, Cordoro KM, Girolomoni G, et al. Association of pediatric psoriasis severity with excess and central adiposity: an international cross-sectional study. JAMA Dermatol. 2013;149:166-76.

5. Sterry W, Strober BE, Menter A; International Psoriasis Council. Obesity in psoriasis: the metabolic, clinical and therapeutic implications. Report of an interdisciplinary conference and review. Br J Dermatol. 2007;157:649-55.

6. Kimball AB, Gladman D, Gelfand JM, Gordon K, Horn EJ, Korman NJ, et al. National Psoriasis Foundation clinical consensus on psoriasis comorbidities and recommendations for screening. J Am Acad Dermatol. 2008;58:1031-42.

7. Duarte GV, Follador I, Cavalheiro CM, Silva TS, Oliveira Mde F. Psoriasis and obesity: literature review and recommendations for management. An Bras Dermatol. 2010;85:355-60.

8. Fitzgerald 0 and Chandran V. Update on Biomarkers in Psoriatic Arthritis: A Report from the GRAPPA 2010 Annual Meeting. J Rheumatol. 2012;39:427-30. still no consensus about which is the best method, WhtR in this sample was quite correlated with obesity in patients with psoriasis, avoiding the problems of using BMI alone, besides presenting a positive correlation with PASI values.

\section{ACKNOWLEDGEMENTS}

To Pedro Dantas and Lídia Machado, dermatologists from Universidade Federal da Bahia, for the enriching critical reading of the work and collaboration on statistical analysis. To Yuri Oliveira for grammatical review.

\author{
MAILING ADDRESS: \\ Gleison Vieira Duarte \\ Ambulatório José Maria de Magalhães Neto \\ Rua Padre Feijó, $\mathrm{S} / \mathrm{N}-3^{\circ}$ andar. Serviço de \\ Dermatologia \\ 40110-170 - Salvador - BA \\ Brazil \\ E-mail: gleisonvduarte@yahoo.com.br
}

How to cite this article: Duarte GV, Silva LP. Correlation between psoriasis' severity and waist-to-height ratio. An Bras Dermatol. 2014;89(5):846-7. 